\title{
ELECTROMYOGRAPHIC STUDY OF CONDITIONS INVOLVING LIMITED MOBILITY OF THE EYE, CHIEFLY DUE TO NEUROGENIC PARESES*
}

\author{
BY \\ ÅKE BJÖRK \\ From the Department of Clinical Neurophysiology, Serafimerlasarettet, Stockholm
}

ELECTROMYOGRAPHY has supplied us with information of great importance in the understanding of the physiology of the muscular system under normal and diseased conditions. Electromyography (EMG) has also become a routine clinical method that is widely used in diagnosis, particularly of pareses.

Not until quite recently was a method devised of obtaining electromyographic recordings from the extrinsic muscles of the human eye (Björk, 1952; Björk and Kugelberg, 1953a). Certain conditions characteristic of the ocular muscles were thereby demonstrated.

Thus the action potentials are smaller than in other human muscles (duration $1.60 \pm 0.06$ milliseconds in the recti). They attain far higher frequencies and recruitment is more rapid than in other muscles (Björk and Kugelberg, 1953a).

It was further shown that, when the eye is in the primary position, all the recti muscles and the levator palpebrae superioris manifest a considerable activity. In simultaneous recording from the internal and external recti it has been shown that, on outward gaze, the activity in the agonist increases greatly, while it falls successively in the antagonist but does not usually disappear even in the extreme outward position (Björk and Kugelberg, 1953b).

A preliminary account of electromyographic studies of paretic eye muscles has been published earlier (Björk, 1952). In the present paper a more detailed report will be given of investigations into cases of paresis due to a lesion of the peripheral motor neuron. Some cases have also been included in which such a lesion has been questioned without a distinct diagnosis being possible by the methods used hitherto.

Neurogenic pareses in other muscles have been studied by many authors, and the myographic picture has therefore already been thoroughly analysed. In lesions of anterior horn cells or motor nerve fibres there is a falling off in the number of action potentials which is largely proportional to the number of nerve fibres that have been put out of function and also to the diminution in muscular force (Lindsley, 1935; Seyffarth, 1938, 1940).

If the lesion is so severe that nerve fibres degenerate, fibrillations occur after 2 to 3 weeks (Denny-Brown and Pennybacker, 1938; Weddell and others, 1944). They consist of small potentials of 1-2 m.sec. duration with an

-Received for publication November 11, 1953. 
irregular or regular fairly slow frequency, and are independent of the voluntary contraction. They appear either quite spontaneously or as a more or less distinct volley on insertion or movement of the needle electrode. Another type of potential, moreover, is often seen, known as sharply rising positive potentials (Jasper and Ballem, 1949; Kugelberg and Petersen, 1949). Both these types of activity provide important clinical information. They indicate that the muscle is denervated, with all that that implies in the prognosis.

\section{Material and Methods}

The subjects of this investigation comprised fourteen cases of ocular muscle palsies (Tables I and II) and ten cases of limitation of ocular movement of obscure origin, 24 cases in all. The majority were examined on two or more occasions, and in about half of the cases several muscles were studied. The time that elapsed between the onset and the first examination in the fourteen cases of palsy was less than 2 months, except in Case 7 when it was 10 months.

The investigation was carried out with the subject in the supine position. The patient was made to fix his gaze on a point of light which could be moved either along a tangent scale on the ceiling or along the arc of a perimeter. The zero point of the scale on the ceiling was placed perpendicularly above the eye and $230 \mathrm{~cm}$. from it. The distance of the arc of the peripmeter from the eye was $35 \mathrm{~cm}$.

The sound and paretic eyes were used alternately for fixation. When the paretic eye was used, the sound eye was covered. Great trouble was taken to get the patient to contract the muscle under examination to the greatest possible extent.

For determination of the position of the paretic eye the angle of deviation was measured, using the arc of the perimeter with a lamp moving along it. While the patient gazed with the sound eye at a small object about $3 \mathrm{~m}$. away the angle of the paretic eye was measured using the corneal light reflex.

The method of recording the electrical activity has been described in earlier reports (Björk and Kugelberg, 1953a). Monopolar needle electrodes were used with the reference needle in the conjunctiva, bridge of the nose or lobe of the ear. To study the activity in the orbicularis oculi muscles a needle was inserted through the skin of the upper or lower eyelid.

Action potentials were amplified by differential amplifiers and the records made with a cathode ray tube and a moving paper camera. When only one amplifier was employed the second beam of the oscilloscope was used for time recording.

\section{Results}

\section{(1) Lesion of Peripheral Motor Neuron}

OCulomotor Palsy.-Seven cases were examined (Table I, overleaf). They showed great similarity as regards aetiology, clinical picture, and course, as exemplified in Cases 1 and 6.

Case 1, male, aged 48, gave a history of sudden total paresis clinically of all external and internal muscles supplied by the 3rd nerve on the left side. Arteriography showed an aneurysm on the left internal carotid near the origin of the posterior communicating artery. About 6 weeks after the onset an operation was performed a silver clamp being placed on the stalk of the aneurysm. Two weeks later the eye was still unchanged (Fig. 1, overleaf). The eye could not be opened at all voluntarily. On gaze to the extreme right the eye stopped in a moderately abducted position.

An electromyogram was taken one week before the operation and again 2 weeks after it, on both occasions on the levator palpebrae and internal rectus muscles. No voluntary 
TABLE I

CASES OF OCULOMOTOR PALSY

\begin{tabular}{|c|c|c|c|c|c|c|}
\hline $\begin{array}{l}\text { Case } \\
\text { No. }\end{array}$ & $\begin{array}{l}\text { Age } \\
\text { (yrs) }\end{array}$ & Sex & Cause & Clinical Picture & $\begin{array}{c}\text { Muscle } \\
\text { Examined }\end{array}$ & $\begin{array}{l}\text { Electromyographic } \\
\text { Record on Maximal } \\
\text { Contraction }\end{array}$ \\
\hline \multirow[t]{4}{*}{1} & \multirow[t]{4}{*}{48} & \multirow[t]{4}{*}{$\mathbf{M}$} & \multirow{4}{*}{$\begin{array}{l}\text { Aneurysm } \\
\text { of internal } \\
\text { carotid }\end{array}$} & \multirow[t]{2}{*}{$\begin{array}{l}\text { Left. Total paresis of } \\
\text { all muscles }\end{array}$} & $\begin{array}{l}\text { Levator } \\
\text { palpebrae }\end{array}$ & \multirow{2}{*}{$\begin{array}{l}\text { No voluntary activity } \\
\text { ? Fibrillations }\end{array}$} \\
\hline & & & & & $\begin{array}{l}\text { Interior } \\
\text { rectus }\end{array}$ & \\
\hline & & & & \multirow[t]{2}{*}{ Left. No change } & $\begin{array}{l}\text { Levator } \\
\text { palpebrae }\end{array}$ & $\begin{array}{l}\text { Voluntary activity } \\
\text { A few potentials } \\
\text { ? Fibrillations }\end{array}$ \\
\hline & & & & & $\begin{array}{l}\text { Internal } \\
\text { rectus }\end{array}$ & \\
\hline \multirow[t]{2}{*}{2} & \multirow[t]{2}{*}{51} & \multirow[t]{2}{*}{$\mathbf{M}$} & \multirow{2}{*}{$\begin{array}{l}\text { Aneurysm } \\
\text { of internal } \\
\text { carotid }\end{array}$} & \multirow[t]{2}{*}{$\begin{array}{l}\text { Left. Total paresis of } \\
\text { all external muscles }\end{array}$} & $\begin{array}{l}\text { Levator } \\
\text { palpebrae }\end{array}$ & \multirow{2}{*}{$\begin{array}{l}\text { No voluntary activity } \\
\text { Probably fibrillations }\end{array}$} \\
\hline & & & & & $\begin{array}{l}\text { Internal } \\
\text { rectus }\end{array}$ & \\
\hline \multirow[t]{2}{*}{3} & \multirow[t]{2}{*}{43} & \multirow[t]{2}{*}{$\mathrm{F}$} & \multirow[t]{2}{*}{$\begin{array}{l}\text { Aneurysm } \\
\text { of internal } \\
\text { carotid }\end{array}$} & $\begin{array}{l}\text { Left. Paresis of all ex- } \\
\text { ternal muscles, in re- } \\
\text { gression. Considerable } \\
\text { ptosis on forward gaze }\end{array}$ & $\begin{array}{l}\text { Levator } \\
\text { palpebrae }\end{array}$ & $\begin{array}{l}\text { Very moderate reduc- } \\
\text { tion of potentials } \\
\text { In some places normal } \\
\text { picture }\end{array}$ \\
\hline & & & & $\begin{array}{l}\text { Further regression. } \\
\text { Limited mobility of } \\
\text { globe on upward gaze }\end{array}$ & $\begin{array}{l}\text { Rectus } \\
\text { superior }\end{array}$ & $\begin{array}{l}\text { Voluntary activity } \\
\text { A few potentials }\end{array}$ \\
\hline 4 & 66 & F & $\begin{array}{l}\text { Aneurysm } \\
\text { of internal } \\
\text { carotid }\end{array}$ & $\begin{array}{l}\text { Left. Paresis in regres- } \\
\text { sion. Considerable } \\
\text { ptosis on forward } \\
\text { gaze }\end{array}$ & $\begin{array}{l}\text { Levator } \\
\text { palpebrae }\end{array}$ & $\begin{array}{l}\text { Voluntary activity } \\
\text { Moderate reduction in } \\
\text { number of potentials }\end{array}$ \\
\hline 5 & 67 & $\mathrm{~F}$ & $\begin{array}{l}\text { Hypertonia } \\
\text { Cerebral } \\
\text { injury }\end{array}$ & $\begin{array}{l}\text { Right. Paresis in re- } \\
\text { gression. Very mod- } \\
\text { erate ptosis }\end{array}$ & $\begin{array}{l}\text { Levator } \\
\text { palpebrae }\end{array}$ & $\begin{array}{l}\text { Voluntary activity } \\
\text { In some places a very } \\
\text { moderate reduction in } \\
\text { number of potentials. } \\
\text { Mainly normal picture }\end{array}$ \\
\hline \multirow[t]{2}{*}{6} & \multirow[t]{2}{*}{50} & \multirow[t]{2}{*}{$\mathrm{F}$} & \multirow[t]{2}{*}{$\begin{array}{l}\text { Skull } \\
\text { fracture }\end{array}$} & $\begin{array}{l}\text { Left. Total paresis of } \\
\text { all muscles }\end{array}$ & $\begin{array}{l}\text { Internal } \\
\text { rectus }\end{array}$ & $\begin{array}{l}\text { Voluntary activity } \\
\text { One potential recruited }\end{array}$ \\
\hline & & & & $\begin{array}{l}\text { Left. Possibly slight } \\
\text { improvement in mo- } \\
\text { bility of globe }\end{array}$ & $\begin{array}{l}\text { Internal } \\
\text { rectus }\end{array}$ & $\begin{array}{l}\text { Voluntary activity } \\
\text { Some potentials }\end{array}$ \\
\hline \multirow[t]{2}{*}{7} & \multirow[t]{2}{*}{69} & \multirow[t]{2}{*}{$\mathbf{M}$} & \multirow[t]{2}{*}{ Hypertonia } & $\begin{array}{l}\text { Left. Total paresis of } \\
\text { all external muscles. } \\
\text { On gaze to extreme } \\
\text { right fixating with } \\
\text { sound eye, left eye } \\
\text { stops } 10^{\circ} \text { outwards }\end{array}$ & $\begin{array}{l}\text { Internal } \\
\text { rectus }\end{array}$ & $\begin{array}{l}\text { Voluntary activity } \\
\text { A few potentials }\end{array}$ \\
\hline & & & & $\begin{array}{l}\text { Left. Improvement. } \\
\text { Eyelid can be raised } \\
\text { a few mm. on maxi- } \\
\text { mum upward gaze }\end{array}$ & $\begin{array}{l}\text { Levator } \\
\text { palpebrae }\end{array}$ & $\begin{array}{l}\text { Voluntary activity } \\
\text { Moderate reduction in } \\
\text { number of potentials }\end{array}$ \\
\hline
\end{tabular}



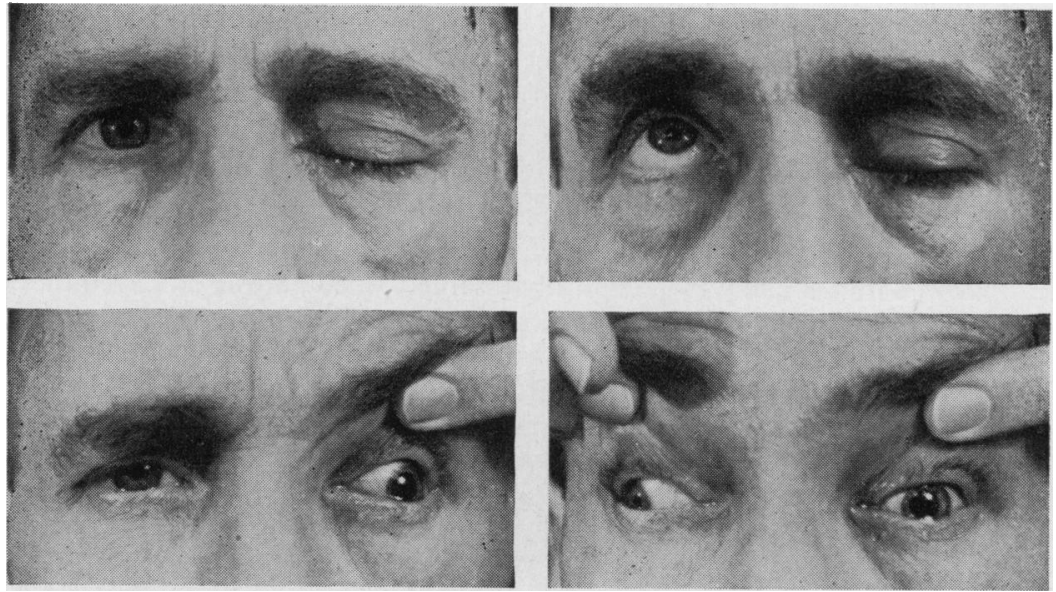

Fig. 1.-Case 1, man aged 48, clinical picture of total left oculomotor palsy. Two upper pictures show eye completely closed on gaze straight ahead and also on strong effort to raise lid when looking upwards. Two lower pictures show position of eye when sound eye looks straight forward and to extreme right respectively. Paretic eye directed outward and slightly downward does not move forward fully to midline. Pupil greatly dilated.

activity was demonstrated in the first study. The second revealed a distinct voluntary activity in these muscles. Thus on maximal contraction a small number of action potentials were mobilized in both muscles (Fig. 2). On observation at high sweep speed the frequency of two different potentials was calculated as 200 and 180 per sec. respectively.

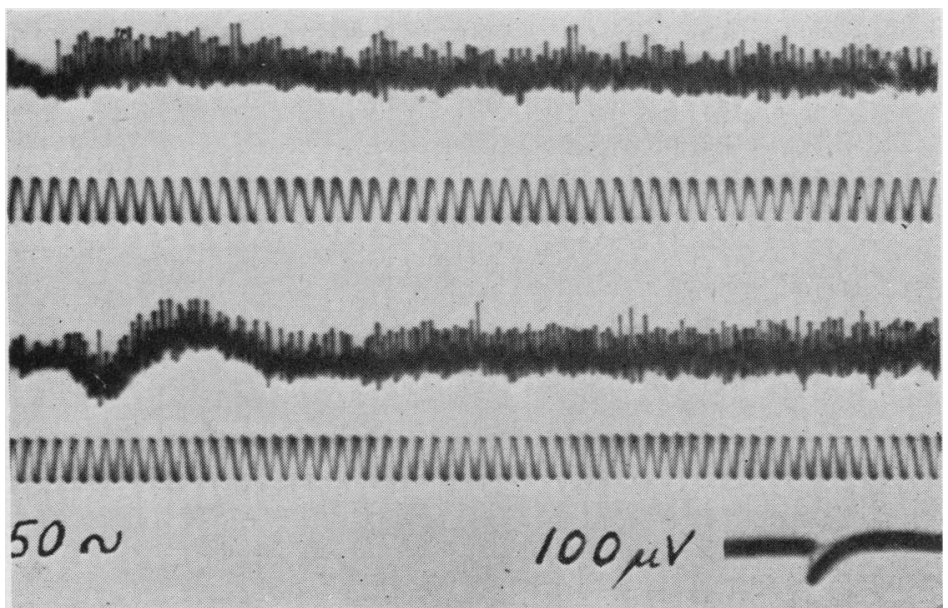

FIG. 2.-Case 1, record from levator palpebrae superioris muscle (upper tracing) and internal rectus (lower tracing) on paretic side. Activity at maximal contraction. Only a few potentials are recruited and these are of high frequency.

In addition some small potentials were observed which appeared to be independent of the voluntary activity and were thus suspected fibrillations.

The occurrence of voluntary activity in the later investigation indicates that an improvement had taken place. The prognosis could therefore be judged favourably, although the presumed presence of fibrillations gave reason to suspect that the recovery would 
be slow. The subsequent course confirmed this. The mobility of the globe and eyelid increased slowly but continuously. Five weeks after the last electromyogram was taken the patient was able to raise the eyelid sufficiently to free the lower half of the pupil and the mobility of the globe to each side was fairly good. Three months later, i.e., over 6 months after the onset, the condition was distinctly improved, but he was troubled by diplopia, particularly when looking far upwards or downwards.

Case 6, female, aged 50, had had a fracture of left temporal bone in a motor-cycle accident, followed immediately by a clinically total left-sided paresis of all muscles served by the 3rd nerve. Examination one month after the accident revealed the same clinical picture of total paresis of all muscles. On gaze to the extreme right the left eye stopped in a position of considerable outward deviation (Fig. 3).
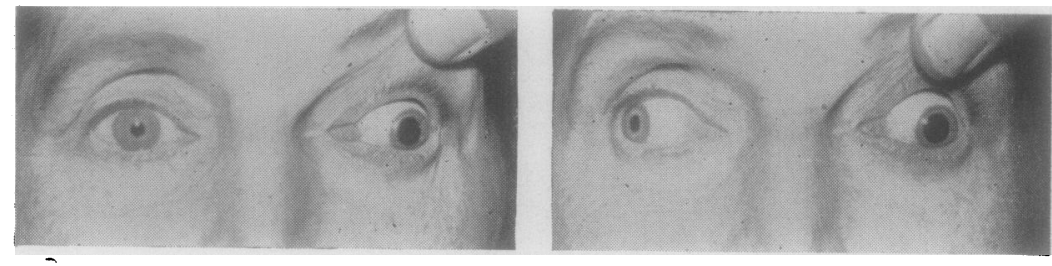

Fig. 3.-Case 6, woman aged 50, clinical picture of total left oculomotor palsy. Pictures show the position of paretic eye when sound eye looks straight forward and to extreme right.

An electromyographic examination was then made of the internal rectus and in several different needle positions showed voluntary recruitment of an action potential which, on a maximum effort of contraction, reached a frequency of 200 per sec. (Fig. 4). This was not therefore a case of total paresis, as the clinical picture had given reason to suppose, and the prognosis could be judged much more favourably. Two weeks later a slight improvement seemed to have occurred, though not distinctly measurable. The electromyogram now showed that some potentials were being recruited, which indicated an improvement. After a further 2 weeks a distinct increase in the mobility of the eye was noticeable. There was continued improvement later, and $2 \frac{1}{2}$ months after the accident the eye could be moved up to $15^{\circ}$ inwards.

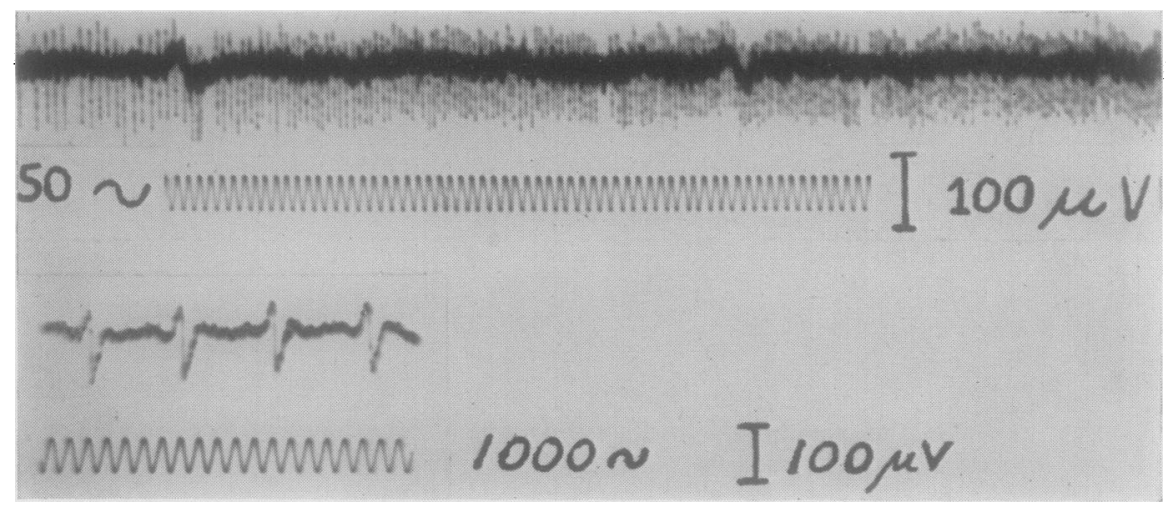

Fig. 4.- Case 6, record from internal rectus muscle on paretic side. An action potential is recruited which attains a high frequency on maximal contraction. Detail picture at high sweep speed shows a frequency of about $200 / \mathrm{sec}$.

The typical electromyographic picture produced by partial injury was also seen 
in Case 3 (Fig. 5). The eye manifested a limited mobility upwards, and the recorded activity in the rectus superior muscle is typical of a severe lesion of the peripheral motor neuron, i.e. a few action potentials of high frequency. In Fig. 5 (upper tracing) an uneven recruitment is noticeable. This occurred when the patient attempted fixation which demanded a powerful upward movement of the eye. She could not maintain an even activation of the available motor neurons. Several potentials of high frequency were mobilized, but after scarcely a tenth of a second one after the other fell out and the frequency of the individual potentials dropped, after which a stronger activation recommenced, and so on. Nor did the eye manifest any continuous fixation, but jerky movements of paretic nystagmus were observed. At times the eye could be kept still, and the activity was continuous with high frequency of the individual potentials (Fig. 5, lower tracing).

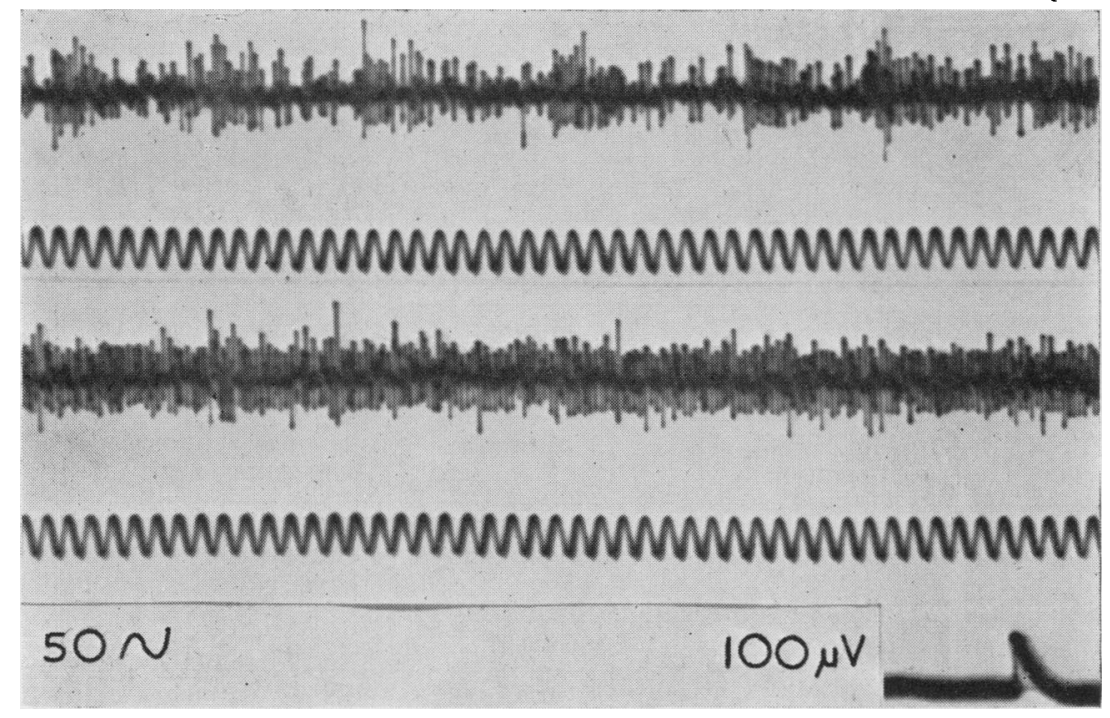

FIG. 5.-Case 3, record from paretic rectus superior muscle on strong effort to look upwards. Upper tracing shows uneven recruitment; this changes at intervals to more even recruitment (lower tracing).

Particularly as regards the levator palpebrae superioris, it is difficult to draw any conclusions from the clinical picture in respect of the real severity of the injury to the peripheral motor neuron. The position and mobility of the eyelid varied greatly with the fatigue of the patient and position of the head. A simultaneous paresis of the rectus superior, which was found in all cases, added further to the difficulty in diagnosis, as also did the patient's tendency actively to close one eye in order to avoid double images. Cases 3 and 4 are examples of considerable ptosis, which may interfere with vision on directly forward gaze, in spite of a very slight reduction in the number of potentials or even, at least during short periods, a normal number.

Abducens Palsy.-Seven cases were studied (Table II, overleaf). The fact that these cases could be examined on several occasions made a more detailed analysis possible. Compared with the cases of oculomotor palsy, these cases presented a more varied aetiology and clinical course. 
TABLE II

CASES OF ABDUCENS PALSY

\begin{tabular}{|c|c|c|c|c|c|}
\hline $\begin{array}{l}\text { Case } \\
\text { No. }\end{array}$ & $\begin{array}{c}\text { Age } \\
\text { (yrs) }\end{array}$ & Sex & Cause & $\begin{array}{l}\text { Position of Paretic Eye } \\
\text { when Sound Eye fixates } \\
\text { Farthest Inwards }\end{array}$ & $\begin{array}{c}\text { Electromyographic Record from } \\
\text { External Rectus Muscle on } \\
\text { Maximal Contraction }\end{array}$ \\
\hline 8 & 53 & $\mathrm{~F}$ & Polyneuritis & Right. $10^{\circ}$ inwards & $\begin{array}{l}\text { Voluntary activity } \\
\text { Moderate reduction in number of } \\
\text { potentials }\end{array}$ \\
\hline \multirow[t]{2}{*}{9} & \multirow[t]{2}{*}{34} & \multirow[t]{2}{*}{$\mathbf{F}$} & \multirow[t]{2}{*}{ Unknown } & Right. $15^{\circ}$ outwards & $\begin{array}{l}\text { Voluntary activity } \\
\text { Reduced number of potentials }\end{array}$ \\
\hline & & & & Right. $30^{\circ}$ outwards & $\begin{array}{l}\text { Voluntary activity } \\
\text { Practically normal picture }\end{array}$ \\
\hline \multirow[t]{2}{*}{10} & \multirow[t]{2}{*}{70} & \multirow[t]{2}{*}{$\mathbf{F}$} & \multirow[t]{2}{*}{$\begin{array}{c}\text { Diabetes } \\
\text { mellitus }\end{array}$} & Left. $5^{\circ}$ outwards & $\begin{array}{l}\text { No voluntary activity } \\
\text { Fibrillations }\end{array}$ \\
\hline & & & & Left. $10^{\circ}$ outwards & $\begin{array}{l}\text { Voluntary activity } \\
\text { Greatly reduced number of poten- } \\
\text { tials }\end{array}$ \\
\hline \multirow[t]{2}{*}{11} & \multirow[t]{2}{*}{59} & \multirow[t]{2}{*}{$\mathbf{M}$} & \multirow[t]{2}{*}{ Unknown } & Left. $10^{\circ}$ outwards & $\begin{array}{l}\text { Voluntary activity } \\
\text { Reduced number of potentials }\end{array}$ \\
\hline & & & & Left. $25^{\circ}$ outwards & $\begin{array}{l}\text { Voluntary activity } \\
\text { No certain reduction in number } \\
\text { of potentials }\end{array}$ \\
\hline 12 & 42 & $\mathbf{M}$ & $\begin{array}{l}\text { Intracranial } \\
\text { operation }\end{array}$ & Right. $15^{\circ}$ outwards & $\begin{array}{l}\text { Voluntary activity } \\
\text { A few potentials }\end{array}$ \\
\hline \multirow[t]{3}{*}{13} & \multirow[t]{3}{*}{57} & \multirow[t]{3}{*}{$\mathbf{M}$} & \multirow[t]{3}{*}{ Unknown } & $\begin{array}{l}\text { Bilateral paresis. (Fix- } \\
\text { ation with contralateral } \\
\text { eye). } \\
\text { Right. } 5^{\circ} \text { outwards } \\
\text { Left. } 5^{\circ} \text { outwards }\end{array}$ & $\begin{array}{l}\text { Right. Voluntary activity. } \\
\text { Greatly reduced number of poten- } \\
\text { tials. Possibly fibrillations }\end{array}$ \\
\hline & & & & $\begin{array}{l}\text { Right. } 15^{\circ} \text { outwards } \\
\text { Left. } 15^{\circ} \text { outwards }\end{array}$ & $\begin{array}{l}\text { Right. Voluntary activity. Re- } \\
\text { duced number of potentials. In } \\
\text { some places almost normal pic- } \\
\text { ture }\end{array}$ \\
\hline & & & & $\begin{array}{l}\text { Right. } 20-25^{\circ} \text { outwards } \\
\text { Left. } 15^{\circ} \text { outwards }\end{array}$ & $\begin{array}{l}\text { Right. Voluntary activity. Normal } \\
\text { picture }\end{array}$ \\
\hline \multirow[t]{2}{*}{14} & \multirow[t]{2}{*}{52} & \multirow[t]{2}{*}{ F } & \multirow[t]{2}{*}{ Unknown } & Left. $5-10^{\circ}$ inwards & Left. No voluntary activity. \\
\hline & & & & Left. Hardly $5^{\circ}$ inwards & $\begin{array}{l}\text { Left. Voluntary activity. One } \\
\text { potential }\end{array}$ \\
\hline
\end{tabular}

The typical picture in lesions of the peripheral motor neuron was clearly demonstrated in this series also. The two following cases (13 and 8) are of special interest.

Case 13, male, aged 57, suddenly developed a bilateral abducens palsy. The eyes were capable of only about $5^{\circ}$ outward movement (Fig. 6, opposite). Recordings from the external rectus muscle of the right eye showed that apparently only one potential was recruited on maximal contraction and that it attained a high frequency (Fig. 6, left recording). In another position of the needle a large, though definitely reduced, number of potentials. 


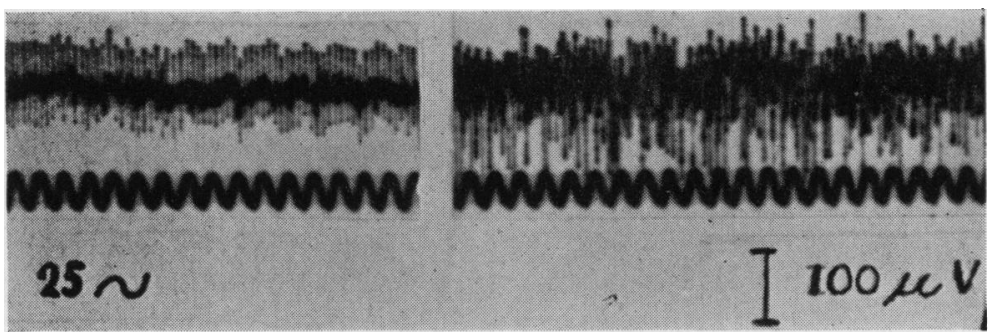

FIG. 6.-Case 13, record from paretic right external rectus on maximum effort to look to right. The two tracings represent two different sites of needle electrode; in first tracing only one potential is seen, in the other several.

were obtained (Fig. 6, right recording).

The right eye could move about $15^{\circ}$ outwards 14 days later. There was now greater activity in the external rectus muscle. A rich supply of potentials was mobilized, so that sometimes an almost normal picture was obtained.

After a further 14 days the right eye could move at least $20^{\circ}$ outwards. A generally normal electromyographic picture was then obtained in the majority of needle positions.

The fact that somewhat different pictures are obtained from different needle positions (which is known in respect of other muscles) applies, of course, to the ocular muscles as well. In Case 13, however, the difference was very striking and showed the necessity of investigations in a number of needle sites. On all three occasions an uneven recruitment was observed, but the picture was somewhat unlike that of Case 3. This was also well demonstrated in Case 8.

Case 8, female, aged 53, had polyneuritis with abducens palsy and flaccid paresis of extremities. The illness had started 10 months previously and no change of eyestatus has been revealed during the last 3 months. On direct forward gaze with the sound eye the paretic eye lay $30^{\circ}$ inwards; on gaze to the extreme right it lay $10^{\circ}$ inwards (Fig. 7).
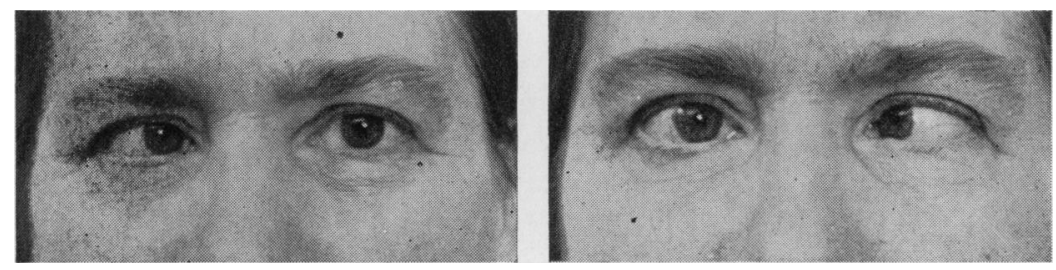

Fig. 7.-Case 8, woman aged 53, right abducens palsy. On directly forward gaze with sound eye, right paretic eye is directed $30^{\circ}$ inwards. On gaze to extreme right, right eye is directed $10^{\circ}$ inwards.

Electromyographic examinations on two different occasions gave concordant results (Fig. 8A, overleaf). When several potentials were recruited, the recruitment took place in such a way that for short periods the individual potentials showed a greater frequency and a tendency to group together. These small bursts, which arrived rather irregularly, were separated by periods of recruitment of only a few single potentials of low frequency.

This picture of uneven recruitment of action potentials which was seen in the above case and also in Case 13 was very characteristic and constant; it was found in most needle positions, and appeared on very moderate effort of contraction. On greater contraction so rich a supply of potentials was recruited that the entire baseline became covered and the characteristic grouping became less and less pronounced. 
In addition to investigations of the number of potentials and their manner of recruitment, observations were made on the size and form of the potentials and the presence of fibrillations.

(i) Size and Form of Potentials.-The form and size of the individual potentials was in most cases similar to that seen in non-paretic eye muscles. A detailed analysis was not always made. In a few cases there were some striking divergences. Thus, in Case 8 , a number of polycyclic potentials were seen, one of which was very broad and of complicated shape (Fig. 8D).

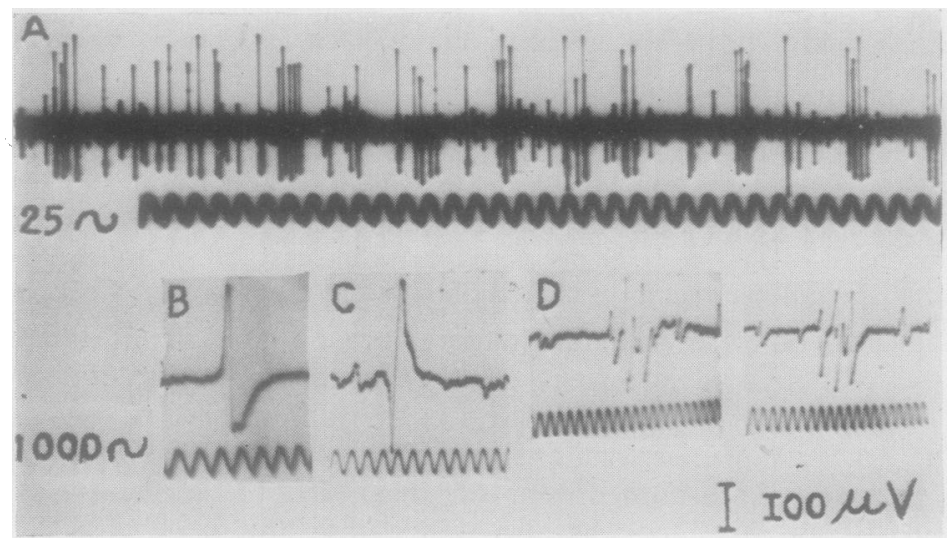

Fig. 8.-Case 8, record from paretic external rectus. On moderate contraction an uneven recruitment is obtained (A). Detail pictures at high sweep speed show that several potentials are of unusually long duration (B and C) or polycyclic (D).

Similar potentials were observed in Case 9, the first examination being made one week after the onset of the paresis when the eye could move $15^{\circ}$ outwards, and the last, 11 days later, when it moved $30^{\circ}$ outwards. On the latter occasion (Fig. 9) the activity was practically normal. A detailed analysis at high sweep speed (Fig. 9, lower tracing), however, showed a number of polycyclic

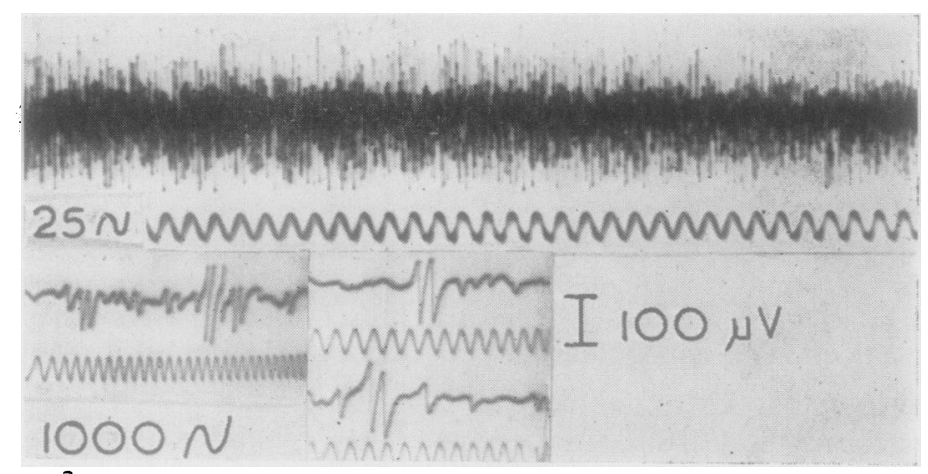

Fig. 9.- Case 9, record from paretic external rectus on maximal contraction (upper tracing) showing abundance of potentials. Detail pictures at high sweep speed (lower tracings) show a few polycyclic potentials. 
potentials. Polycyclic potentials were also observed at the first examination. In Case 13, likewise, several very broad polycyclic potentials were seen.

It has long been known from other muscles (Weddell and others, 1944) that an abundance of polycyclic action potentials is found chiefly on regeneration of the nerve fibres.

The possible occurrence of fibrillations and the clinical course are naturally significant factors in assessing whether a regeneration exists. In Case 8 the paresis had already been present for ten months when the first examination was made. No fibrillations were found, but it is of interest that they were demonstrated in several of the extremity muscles. In Case 13, with bilateral abducens palsy, fibrillations may possibly have existed. The restitution was fairly rapid and a clinical improvement was noted after only three weeks. Case 9 manifested an improvement in mobility after about one week and the regression was rapid throughout.

Whether or not reinnervation took place in these cases is, of course, difficult to decide. Perhaps a reinnervation occurs very rapidly in the ocular muscles.

No certain explanation can be given, either, of the strikingly large potentials observed in two of the cases. Potentials of abnormally long duration, without being polycyclic, were demonstrated in conjunction with polycyclic potentials in Case 8 (Figs 8 B and $\mathrm{c}$ ), several of them having a duration of about $3 \mathrm{~m} . \mathrm{sec}$. Similar potentials were also seen in Case 11. Potentials of this kind may be associated with a picture of regeneration. In chronic nerve lesions it is known that in other muscles potentials of high amplitude (Denny-Brown and Pennybacker, 1938; Kugelberg 1947, 1949; Yahr and others, 1950) and of long duration (Buchtal and Clemmesen, 1941) appear.

(ii) Fibrillations.-These are difficult to recognize because the ocular muscles cannot with certainty be relaxed to the point where all voluntary activity disappears. Their recognition is also difficult since their appearance is similar to the voluntary potentials of the ocular muscles. In Case 10, however, fibrillations were observed with certainty. The patient, a 73-year-old woman, was examined 3 weeks after the onset of the paresis. The eye could not move more than $5^{\circ}$ outwards, and no voluntary activity was found during the electromyographic examination. On the other hand, small potentials were seen (Fig. 10, overleaf) which were independent of the position and movements of the eye. They had an irregular, slow frequency, and lasted uninterruptedly for over half an hour. Ten days later the picture was clinically unchanged. The electromyographic examination showed fibrillations, though in less profusion than earlier. Voluntary activity was demonstrable seven weeks after the onset. An improvement in mobility was noticed at the same time, and after 4 to 5 months the mobility was practically normal. 


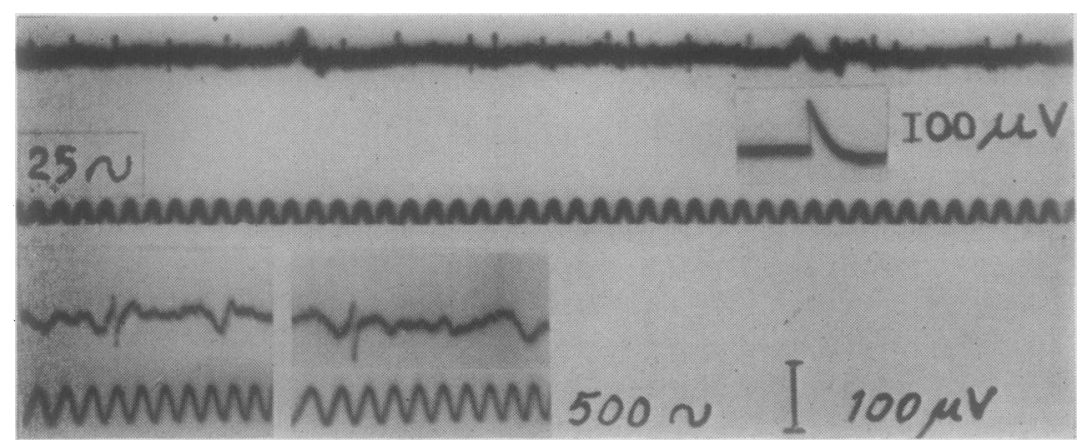

FIG. 10.-Case 10, record from paretic external rectus. Upper tracing shows fibrillations. Lower tracing shows detail picture at high sweep speed with spikes of about $85 \mu \mathrm{V}$ amplitude and $0.5 \mathrm{~m} . \mathrm{sec}$. duration.

In Case 2 an activity was observed that was probably due to fibrillations. Activity highly suspicious of fibrillations was also observed in Case 1 , as mentioned above.

The presence of fibrillations indicates that, if restitution occurs, it will proceed slowly; this is confirmed by the three cases referred to.

Mobility of Paretic Eye and Electromyographic Findings.-To assess the degree of the paresis by ordinary clinical methods is easier in abducens palsy, as only one muscle is paralysed, than in oculomotor palsy. A comparison between the mobility of the paretic eye and the electromyographic findings in abducens palsy can be made from the data in Table II.

The limitation in the outward movement of the eye, which characterizes a total paresis, varies from case to case within quite wide limits. This is, for example, apparent in Cases 8 and 10. In Case 10 the eye could be moved $5^{\circ}$ outwards and no voluntary activity was recorded electromyographically from the external rectus, while in Case 8 the eye stopped $10^{\circ}$ inwards in spite of a quite considerable voluntary activity. It follows therefore that the normal clinical methods are inadequate for determining whether a paresis is total or not.

The greater the capacity of the eye to move outwards, the more certain it is, of course, that a voluntary activity will be found in the external rectus. Activity has also been demonstrated in the cases in which the eye could be moved $10^{\circ}$ outwards or more.

In oculomotor palsy a determination of the severity of the paresis from the mobility of the eye appears to be even more problematical. In Case 6, as already mentioned, the paresis appeared to be clinically total in all extrinsic muscles. On maximum movement in the direction of the sound eye, the paretic eye stopped at $25^{\circ}$ outward deviation. In spite of this manifestly poor mobility voluntary activity was not lacking in the internal rectus. 
In clinically mild or moderately pronounced pareses it often happens that no definite reduction in the number of potentials is noticeable on myographic examination. Examples of this are Cases 9 and 11, in which a clinically manifest abducens paresis was present and the paretic eye could be moved $30^{\circ}$ and $25^{\circ}$ outwards respectively.

In some cases of loss of voluntary activity in the external rectus, the activity has been examined in the sound antagonist as well, that is in the internal rectus. It was found that, when the gaze was in the direction of the paretic muscle, a successive diminution of activity took place in the internal rectus, roughly the same as if the eye performed its normal movement. This observation is of help in the understanding of the reciprocal innervation of the ocular muscles, which will be dealt with in greater detail in a later paper.

\section{(2) Mechanical Factors impeding Movement of the Eye}

A dislocation of the globe due, for example, to trauma or to space-occupying lesions in the orbit may cause a limitation in its movement that simulates or conceals an eye muscle paresis. Two cases have been examined in which the globe was dislocated by atrophy of the orbital fat following trauma; in one case this was combined with a fracture that caused inter alia a lowering of the floor of the orbit.

Case 15, male, aged 51, gave a history of trauma in the right orbital region, without bone fracture or damage to the globe, which caused within the course of a few months an atrophy of the orbital fat, whereby the globe was dislocated inwards and downwards towards the floor of the orbit. The movement of the globe was limited, particularly upwards. On gaze straight ahead and fixation with the left eye, the right eye was directed $5^{\circ}$ downwards. On raising the gaze to the upward maximum, the right eye moved very little and stopped at a maximum of $10^{\circ}$ upwards (Fig. 11). On downward gaze there was no restriction of mobility. Laterally there was good mobility, but a slight limitation of outward movement.
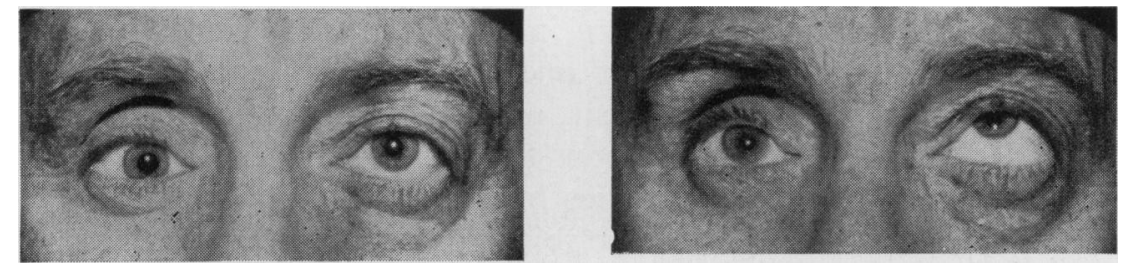

FIG. 11.-Case 15, male aged 51, dislocation of right eyeball following trauma. On gaze straight ahead with left eye, right eye is directed slightly downwards. On extreme upward gaze, right eye is directed $5-10^{\circ}$ upwards.

An electromyographic recording from the rectus superior of the right eye showed no signs of lesion of the peripheral motor neuron. On fixation with the left eye on an object which moved from below upwards until the patient could no longer see it, the electromyogram from the right eye showed a continuously increasing activity, apparently quite independent of the limitation of movement-roughly as though the recording had been taken from the sound eye. When the right eye was directed straight ahead, an 
abundance of potentials was observed (Fig. 12B). A considerable increase was seen on maximum upward gaze (Fig. 12C). Between these positions the right eye moved 5-10 .

During examinations of the superior rectus care must be taken to avoid the error of recording instead from the levator palpebrae superioris. This possibility was excluded by examining the activity during blinking as well. Simultaneous recordings were taken from the orbicularis oculi with the needle in the lower eyelid (Fig. 12A). The recording revealed a short increase in activity in connection with blinking. This cannot be referable to the levator, since in the latter muscle a strong momentary inhibition of the activity takes place on blinking (Björk and Kugelberg, 1953b).

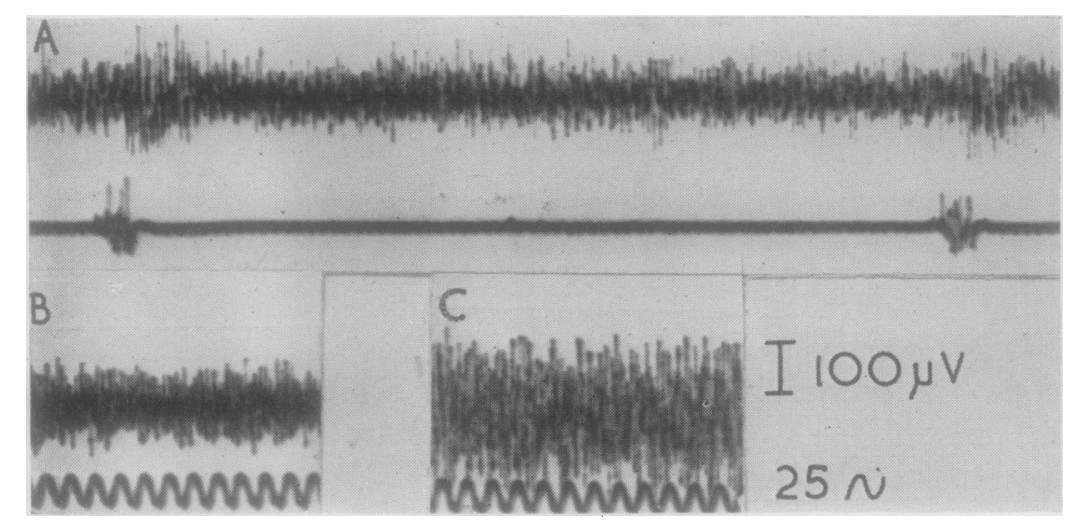

FIG. 12.- Same case as shown in Fig. 11.

(A) Simultaneous recording from right rectus superior (upper tracing) and from orbicularis oculi with needle in right lower eyelid (lower tracing). During blinking a momentary increase in activity takes place in rectus superior.

(B) Activity in rectus superior when right eye is directed straight ahead.

(c) Considerably increased activity, on maximal upward gaze. Fixation with sound eye in both instances.

The examination showed that there could be no severe injury of the peripheral motor neuron. This leads one to assume that the dislocation of the globe was the main cause of limited movement. The second case examined manifested identical conditions in all essential respects.

Limitations of movement that are innate or acquired in early childhood form a quite common group, but one that presents difficulty in clinical diagnosis. It includes nuclear aplasia, defective development of the muscles, abnormal tendon attachments, various kinds of childbirth lesion, and so on.

The cases present many difficulties in electromyographic examination as well. Technical problems arise due to the often abnormal topography and extreme thinness of the muscles. In some cases, however, an electromyographic study has been carried out successfully. For example, in two cases in which a total paresis was supposed, a good activity was revealed electromyographically.

\section{Discussion}

The method employed for the solution of a number of questions concerning the electrophysiology of ocular muscles (Björk, 1952; Björk and Kugelberg, $1953 \mathrm{a}, \mathrm{b})$ has proved applicable, too, to the examination of pathological cases. 
To study a paretic or suspected paretic muscle, an examination must be made in several different needle sites. This is of particular importance in myopathies and in denervation. The anatomical conditions are such, however, that certain portions of the ocular muscles are inaccessible, and at times it is difficult to obtain a suitable needle position at all. As it is not known exactly where in the muscle the point of the needle lies, it is probable that recordings are on many occasions taken from superficial positions or within the junction between the tendon and the belly of the muscle involving a very small pick-up range for the needle. This may possibly be the explanation why different sites have at times manifested a strikingly large difference in the number of action potentials that can be mobilized. Thus the limitations attaching to the method itself imply certain limitations in the possibilities of diagnosis.

The fundamental features in the electromyographic picture characteristic of a lesion of the peripheral motor neuron are also found in respect to the ocular muscles. The investigation has shown that a reduction in the number of potentials on voluntary contraction follows essentially the same pattern as in other muscles, but that it is impossible to demonstrate this reduction in cases of pareses of only moderate clinical severity. The explanation lies in the fact that the ocular muscles bring into play a particularly abundant quantity of potentials, so that, despite the disappearance of many of them, pictures manifesting a profusion of interfering potentials are still seen.

An uneven recruitment is often seen in a paretic eye muscle and may behave electromyographically in different ways. Thus on even slight contraction, involving the recruitment of few potentials, it is seen that they appear in small bursts between intervals of more sparse recruitment. With a rising effort of contraction the picture can be followed as long as not too many potentials are mobilized, when the picture becomes less characteristic.

Another picture may also occur on strong contraction, particularly when the number of potentials is greatly reduced: rapid recruitment of a number of potentials of high frequency, gradual diminution in frequency and disappearance of potentials, so that the activity sometimes falls to zero, again rapid recruitment, and so on. These pictures may vary considerably in different cases and on different occasions.

In uneven recruitment an ordinary inspection will normally reveal that the eye makes small jerky movements. These movements are observed still more clearly if, in addition to electromyographic examination, some detail in the fundus is examined through an ophthalmoscope. It is thus a question of paretic nystagmus. This may appear in various forms, both clinically and electromyographically, and will be analysed more closely in connection with nystagmus (to be published).

The rapid fatigue which distinguishes a palsied muscle is admirably revealed by electromyographic examination of paretic eye muscles, and possibly paretic nystagmus is also one of its manifestations. A remarkably 
vigorous electrical activity can be obtained from a sudden effort of contraction, but the potentials can only be mobilized momentarily. In fairly pronounced pareses, therefore, there may be short periods in which the pictures appear quite normal. A vigorous effort of contraction is most conveniently obtained by covering the sound eye and getting the patient to fixate with the paretic eye. The effort to follow an object with the gaze within the area of activity of the paretic muscle mobilizes an innervation impulse which is stronger than that produced by fixation with the sound eye in its extreme positions.

As has been shown earlier (Björk and Kugelberg, 1953a), very high frequencies of the remaining potentials may be observed in paretic eye muscles, often up to about 200 per second. This was confirmed in the cases now investigated. The demonstration of high frequencies is significant as evidence that a vigorous effort of contraction has taken place. In eye muscle pareses a good check on the effort applied is also obtainable by observation of the position and movements of the sound eye. It has at times proved difficult or impossible to obtain high frequencies in spite of an apparently vigorous effort of contraction. This fact is known from severe pareses in other muscles and is probably due to failure of proprioception from the paretic muscle (Kugelberg, 1953).

Fibrillations are difficult to demonstrate in ocular muscles (Björk, 1952). The eye muscle potentials are normally of about the same appearance as fibrillations, and therefore other criteria must be sought, in particular that the fibrillations shall be independent of the voluntary contraction. Since complete voluntary relaxation of an eye muscle is not possible to achieve with certainty, it is mainly in cases of entire absence of voluntary activity that we are enabled to find fibrillations. Also, since the whole muscle is not accessible to examination, it may happen that fibrillations are not discovered. These difficulties explain the uncertainty in diagnosing some of the cases reported with respect to denervation and reinnervation.

All methods employed hitherto for assessing the severity of an eye muscle paresis and following its course are based on recording of the position and movements of the eye. The present investigation has shown that, in the assessment particularly of severe pareses, the electromyographic study can provide information that cannot be obtained by other methods.

When the limitation of movement in a paresis is of great severity, the picture of total paresis is encountered. The degree of limitation to be expected is apparent in the remarks of Cogan (1948):

Oculomotor Palsy.-When the non-paralysed eye is fixating straight ahead, the paralysed eye is held in a position of divergence but can be brought to the midline by directing the gaze to the side opposite the paralysis.

Abducens Palsy.-Convergent strabism with inability to turn the eye lateralward beyond the midline.

The electromyographic examination gives us exact information concerning the voluntary activity. When we relate this information to the clinical 
picture, we find that voluntary activity is often manifested where the clinical picture suggested a diagnosis of total paresis. This is perhaps particularly striking in the oculomotor palsies. Thus in one case a distinct voluntary activity was demonstrated in the internal rectus muscle although the eye could not reach anywhere near the midline but stopped at $25^{\circ}$ outward deviation on maximum outward fixation with the sound eye.

The course of severe pareses can be very accurately followed by electromyographic means. The number of action potentials is in these cases greatly reduced, and a slight alteration will therefore be readily noticeable. Such an alteration may occur without any change in the clinical picture. The action potentials of the ocular muscles are, as was shown earlier, small and must be assumed to represent weak motor units. This would seem to apply to a very marked extent to the small potentials which may appear at the beginning of a reinnervation.

The position assumed by the paretic eye depends upon many factors. It has been shown earlier that in normal cases, when the eye is in the primary position the motor unit activity is very considerable in all the recti (Björk and Kugelberg, 1953b). It is therefore natural that, in paresis of one or more muscles, the eyeball is strongly pulled in the direction of the sound antagonists. Other factors may also affect the dislocation; it will be sufficient here to mention the significance of a possible latent strabism which is manifested on disturbance of the binocular vision.

Limitation of the movement of the eye may be brought about, not only by neurogenic pareses, but also by other causes such as muscular affections and purely mechanical factors. Oedema and bleeding in the eyelid and orbit are examples of this, as is also a dislocation of the eyeball in connection with traumata of the orbital region. Other examples comprise congenital disturbances involving under-development of the muscles, abnormal tendon attachments, etc.

The investigation has shown that electromyography is an aid in differential diagnosis between these aetiologically quite distinct conditions.

\section{Summary}

An electromyographic investigation was made of ocular muscles in 24 patients with limited mobility of the eyeball, including fourteen cases of typical eye muscle palsy and two cases in which the main cause was assumed to be due to mechanical factors. In the remainder of the cases the cause was less distinct.

\section{(1) Lesion of Peripheral Motor Neuron}

(a) Number and Form of Action Potentials.-A reduction in the number of action potentials has been observed, the chief features of which accorded with experience from other muscles.

The duration and form of the action potentials seemed in most cases to be 
the same as in non-paretic eye muscles. Some divergences have been observed, e.g. an abundance of polycyclic action potentials in three cases.

(b) Fibrillations.-This important sign also occurs in the ocular muscles and was definitely observed in one case and appeared probable in two others. Since they have the same appearance as the normal action potentials and complete voluntary relaxation of an eye muscle is not possible to achieve with certainty, they are difficult to diagnose.

(c) Uneven Activation.-In a number of the cases the recordings showed an uneven activation of the residual action potentials of characteristic appearance. At the same time small jerkings of the eyeball were observed, so called paretic nystagmus.

(d) Paresis.-By aid of electromyography it is possible to decide whether an eye muscle paresis is total. In this respect the clinical methods of examination are unsatisfactory. It was thus shown that in cases of paresis, which were clinically diagnosed as total, a voluntary activity was manifested in the electromyographic examination.

The course of the severe pareses can be followed with great accuracy electromyographically, for, as long as the number of action potentials is fairly small, even very slight changes are easily noticeable. These small changes often occur without any change at all in the clinical picture.

In moderately pronounced or mild cases of paresis no reduction in the number of action potentials is as a rule observed by the methods used here.

\section{(2) Mechanical Factors causing Limitation of Movement}

In two cases involving change of the anatomical conditions in the orbit following trauma, it was shown that electromyography assists in differentiating between ocular muscle paresis and limitation of movement due to mechanical factors.

In some indistinct cases, as in congenital limitation of movement, electromyographic examination can be of aid in diagnosis.

\section{REFERENCES}

Bü̈RK, А. (1952). Experientia, 8, 226.

, and Kugelberg, E. (1953a). Electroenceph. clin. Neurophysiol., 5, 271.

Buchthal, F., and Clemmesen, S. (1941). Acta psychiat. neurol. (Kbh.), 16, 143.

CogAN, D. G. (1948). "Neurology of the Ocular Muscles". Thomas, Springfield, Ill.

DENNY-Brown, D., and PenNYBaCKer, J. B. (1938). Brain, 61, 311.

JASPER, H., and BAllem, G. (1949). J. Neurophysiol., 12, 231.

Kugelberg, E. (1947). J. Neurol. Neurosurg. Psychiat., 10, 122.

- (1949). Ibid., 12, 129.

- (1953). Personal communication.

$\longrightarrow$, and Petersen, I. (1949). J. Neurol. Neurosurg. Psychiat., 12, 268.

Lindsley, D. B. (1935). Amer. J. Physiol., 114, 90.

SEYFFARTH, H. (1938). Acta psychiat. neurol. (Kbh.), 13, 297.

(1940). Skr. norske Vidensk.-Akad., I. Mat.-nat. Kl., No. 4.

Weddell, G., Feinstein, B., and Pattle, R. E. (1944). Brain, 67, 178.

YAHR, M. D., Herz, E., Moldaver, J., and Grundfest, H. (1950). Arch. Neurol. Psychiat. (Chicago), 63, 728. 